\title{
AS TRANSFORMAÇÕES DO MUNDO ATUAL E O DIREITO: CIDADANIA E GLOBALIZAÇÃO
}

\author{
CHANGING THE WORLD TODAY AND THE RIGHT: \\ CITIZENSHIP AND GLOBALIZATION
}

Valéria Ribas do Nascimento ${ }^{1}$

Aline Andrighetto ${ }^{2}$

\begin{abstract}
RESUMO - Com a chegada do século 21, diversas transformações ocorreram no mundo e, com elas, novidades econômicas, tecnológicas e sociais. O que o homem necessita é aprender a trabalhar e adaptar-se dentro deste meio, pois é o avanço nas mais diversas áreas do conhecimento que o leva a melhorar as relações do cotidiano. Mas há ainda outra necessidade primordial - a de conscientizar o ser humano, como cidadão, da sua situação perante as inovações trazidas com a chegada da globalização. As preocupações com as minorias, com o desemprego, saúde, educação, alimentação, entre outros, fazem com que seja de suma importância melhorar e buscar conhecimento para se adaptar às inovações pelas quais tem passado o mundo neste momento e participar como cidadão ativo deste processo de globalização.
\end{abstract}

Globalização.

PALAVRAS-CHAVE - Transformações. Necessidades. Cidadão.

ABSTRACT - Reached twenty-first century, several changes occurred in the world and with them new economic, technological and social. What man needs is to learn to work and fits into this country because it is the breakthrough that leads us to improve the relations of everyday life. But there is another fundamental need to raise awareness of the human being as a citizen of his situation with the innovations introduced with the advent of globalization. Concerns about minorities, such as unemployment, health, education, food, among others, make it of paramount importance to improve and seek knowledge for adapting innovations suffered by the world at this time and participate as active citizens of this globalization process.

KEYWORDS - Transformation. Needs. Citizen. Globalization.

1 Doutora em Direito pela Universidade do Vale do Rio dos Sinos (Unisinos). Pesquisadora CNPQ/CAPES. Professora Adjunta do Curso de Direito da Universidade Federal de Santa Maria (UFSM). E-mail: valribas@terra.com.br.

${ }_{2}$ Bacharel em Direito e pós-graduada em Direito Ambiental pela Universidade Regional do Noroeste do Estado do Rio Grande do Sul (Unijuí). Mestranda em Direito e Multiculturalismo pela Universidade Regional Integrada do Alto Uruguai e das Missões (URI). E-mail: alineandrighetto@gmail.com. 


\section{CONSIDERAÇÕES INICIAIS}

O presente estudo visa a analisar a situação do cidadão com a globalização e as dimensões de benefícios e malefícios oriundos do processo, ou seja, busca uma visão social de mundo e das relações da sociedade com tantas mudanças tecnológicas e sociais.

Chegado o século 21, as mudanças e transições trazem novidades econômicas, tecnológicas e sociais, mas há ainda a necessidade de conscientizar o ser humano, o cidadão em si, de sua situação perante essas transformações $\mathrm{e}$ demonstrar que mesmo com benefícios, existem situações às quais o homem precisa se adequar, e quem não as acompanhar, não compartilhará dos seus benefícios. Isto se deve à situação econômica e social em que o mundo vive hoje. As taxas de pobreza estão se elevando a cada dia e não há que se cobrar da população a sua inserção neste mundo globalizado, com tantas novidades consumistas.

No Brasil também podem ser analisados traços deste paradigma. A crise da cidadania demonstra que tem seu principal fundamento na falta de interesse da população por informações.

A falta de cultura, de condições sociais e econômicas de sobrevivência fazem do Brasil um país lento e ainda criterioso com as novidades trazidas com a globalização. Há de se falar da forte aliança econômica da qual o Brasil faz parte e que propõe uma nova visão, uma chance de melhora dos negócios internacionais. $A$ partir deste espera-se que com o crescimento econômico do país se possa, consequentemente, melhorar as relações sociais e culturais, deixando o país num patamar um pouco mais elevado no que se refere a mecanismos internacionais e nacionais de modernização e globalização.

\section{O MUNDO E SUAS TRANSFORMAÇÕES}

O século 21 está envolvido com problemas provindos de sua hegemonia que acabam afetando o sistema estatal em suas faces política, econômica e social. Como se fala que este período está em constante mudança, pode-se observar a 
chegada do processo de globalização. Este já se tornou parte de nosso cotidiano, desafiando um grande número de pessoas no Planeta Terra com seus problemas e possibilidades.

Segundo Giddens (1991, p. 69-70):

A globalização pode assim ser definida como a intensificação das relações sociais em escala mundial, que ligam localidades distantes de tal maneira que acontecimentos locais são modelados por eventos ocorrendo a muitas milhas de distância e vice-versa. Este é um processo dialético porque tais acontecimentos locais podem se deslocar numa direção inversa às relações muito distanciadas que os modelam.

O mundo se transformou, não existem mais fronteiras, os meios de comunicação, transição e informação são universais. As descobertas científicas espalham-se pelo mundo; a imprensa e a eletrônica transformaram o mundo em um verdadeiro show de imagens e paraísos. Dentro deste contexto observa-se uma linha social de criação de espaços de luta por uma sociedade justa e igualitária, que com estes avanços se vê prejudicada.

A cidadania, definida por princípios de justiça e igualdade, é posta à prova e a população deve buscar em seus princípios, um ideal de direitos e deveres para que possa abrir espaço neste novo mundo que toma grandes proporções ideológicas e tecnológicas.

\subsection{Globalização: conceituação e dimensões}

O processo de globalização já se tornou presente no cotidiano das pessoas em todo mundo. Para alguns doutrinadores, essa expressão tornou-se marco de crescimento e ascensão de investimentos financeiros internacionais, mas para outros não passa de uma simples "construção ideológica", usada pela imprensa para atrair exploradores a determinados países em desenvolvimento.

O resultado são as mútuas transformações entre o local e o global. As cidades, os países e os continentes são influenciados não apenas por aspectos internos ou por seus vizinhos, mas também pelo dinheiro mundial, mercado de bens e organizações internacionais [...]. (NASCIMENTO, 2011, p. 106). 
O que se pode salientar é que a estruturação do mundo como um sistema global é um dos maiores passos político, econômico e social das últimas décadas, constituindo uma fase histórica que objetiva possibilidades concretas e a modificação de paradigmas existentes na sociedade. Assim, o processo de globalização transforma-se em estágio de internacionalização e amplificação de negócios, comunicação e ciência pelo mundo.

Associado normalmente a processos econômicos, circulação de capitais e ampliação dos mercados mundiais, a globalização participa também das áreas de atuação social, padroni-zando relações culturais, como desarmamento, crescimento da população e direitos humanos.

Os principais aspectos observados no processo de globalização são de relação social, econômica, padrões de vida e cultura, transformação do Estado e da política. O que nos cabe analisar, também, é o aumento de contatos internacionais, a difusão de novas tecnologias e a internacionalização do conhecimento social. Em conjunto, estes aspectos dão uma nova visão de aspecto global, iniciando uma etapa distinta de forças unificadas mundiais.

Segundo Vieira (2001, p. 93):

\begin{abstract}
Uma das consequências fundamentais da globalização é a convivência problemática entre a lógica do poder territorializado e a do poder crescentemente desterritorializa-do do capitalismo globalizado. Diante das novas condições de internacionalização da produção, do comércio e das finanças, tornam-se evidentes as restrições que seu funcionamento e suas forças dominantes impõem à soberania e às margens de autonomia dos Estados nacionais, bem como a seu papel de agente do desenvolvimento econômico e garantidor da coesão e integração social e nacional.
\end{abstract}

O Planeta se unificou, as fronteiras para o conhecimento foram abolidas, 0 desenvolvimento da humanidade teve consideráveis transformações, tornando um acontecimento instantâneo em qualquer parte do mundo.

Este fenômeno, como é chamado, faz uma configuração mais ampla e complexa do mundo, possibilitando a consolidação de projetos político-ético-globais, ou seja, projetos de uma ordem mundial mais justa e solidária. É um momento de compreensão e troca de experiências com todas as consequências e possibilidades de suas descobertas para a ordem social e para o cidadão. 
Dentro deste contexto pode-se ainda enfocar algumas dimensões, as quais farão diferença no tocante à conceituação e problematização deste assunto.

Com relação ao aspecto econômico pode-se dizer que o mercado tornou-se estrutura da humanidade, cujas proporções estão dominando o mercado financeiro. Como bom exemplo desta expressão tem-se o chamado G- $7^{3}$ ou G-8 (atualmente chamado), que agrega o grupo dos sete países mais ricos do mundo, mais a Rússia, e que praticamente controla as ações financeiras globais. Também se pode citar organizações como a Organização Mundial do Comércio (OMC), que desempenha um papel importante no que se refere às negociações de importação e exportação e ao trabalho desenvolvido por operários (mão de obra) neste âmbito internacional. Enfim, neste sentido, o processo de globalização tem fortalecido grandes poderes para colaborar na internacionalização e evolução das finanças.

Nas palavras de Ferrajoli (2002, p. 48-49):

O Estado nacional como sujeito soberano está hoje numa crise que vem tanto de cima quanto de baixo. De cima, por causa da transferência maciça para sedes supra-estatais ou extra-estatais (a Comunidade Europeia, a OTAN, a ONU e muitas outras organizações internacionais em matéria financeira, monetária, assistencial e similares) de grande parte de suas funções - defesa militar, controle da economia, política monetária, combate a criminalidade [...].

Já na dimensão política, o Estado atua como principal ator, pois com a chegada do século 21, entidades e instituições governamentais como a Organização das Nações Unidas (ONU), a União Europeia e outras, as quais existem para assessorar projetos de desenvolvimento e igualdade social orientados pela entidade estatal, intensificaram seus projetos e atuam de maneira mais significativa em casos concretos.

$\mathrm{Na}$ esfera social pode-se dizer que o processo de globalização trouxe problemas de forma descontrolada para a população de alguns países considerados subdesenvolvidos. Com o crescimento populacional desenfreado as dificuldades econômicas enfrentadas tornaram-se desesperadoras, pois as preocupações com necessidades básicas de sobrevivência foram deixadas de lado, ou seja, foram abertos tantos caminhos à tecnologia, às novas estruturas sociais com pensamentos cada vez mais ambiciosos, que acabou causando uma luta de classes muito grande.

${ }^{3}$ Estados Unidos, Alemanha, Canadá, França, Itália, Japão e Reino Unido. 
Ora se observa a luta pela sobrevivência de alguns com a busca de condições dignas de vida e ora se vê o desperdício por parte de outros com tantos luxos. Neste contexto, o processo de globalização deixa a população cada vez mais descontente com seu progresso, por não possuir condições de acompanhá-lo.

\begin{abstract}
Um novo mundo está tomando forma, com origem no final dos anos sessenta a início dos anos setenta, através de três processos independentes: a revolução da tecnologia da informação; a crise econômica tanto do capital como do estatismo e suas subsequentes reestruturações; o florescimento de movimentos sociais e culturais, como o antiautoritarismo, a defesa dos direitos humanos, o feminismo e o ecologismo. A integração entre esses processos e as relações que desencadearam estão criando uma nova estrutura social dominante; a sociedade de rede, 'uma nova economia, a economia informacional-global; e uma nova cultural, a cultura virtual-real. A lógica inserta nessa economia, nessa sociedade e nessa cultura estão subjacentes na ação social e nas instituições de um modo interdependente. (CASTELLS, 1998, p. 369- 370).
\end{abstract}

No que se refere a questões culturais pode-se dizer que o mundo se rendeu à cultura norteamericana, nas palavras, roupas, gostos musicais, comidas, etc. O que se observa é que o processo de globalização deixou a população confusa com tantas novidades e com a universalização da língua inglesa, mas o acesso da população desinformada e carente a essa realidade está cada vez mais difícil.

Para melhor compreensão deste fenômeno que se apresenta ao mesmo tempo paradoxal e contraditório, é necessário abordar os tipos de globalização e em que área de atualização ela está mais presente. A partilha de bens materiais e o acesso de todos ao que é comum não pode ser entendido como universalização (FARIA, 2002, p. 52). Esse fenômeno produz um impacto muito grande na sociedade, por isso será analisado de forma diferenciada.

Depois de conceituar globalização e enumerar as diferentes dimensões (esferas) de atuação deste fenômeno, abordar-se-á suas áreas de atuação, enfocando a globalização econômica, política e social para melhor compreensão deste fenômeno:

a) Econômica: ao analisar o número de negócios realizados por grandes empresas (transnacionais) e o valor financeiro que estes representam no mundo pode-se dizer que quem comanda o setor econômico mundial são tais empresas, controladoras do mercado financeiro.

Na visão de Vieira (2002, p. 81): 
os agentes mais dinâmicos da globalização não são governos que formaram mercados comuns em busca da integração econômica, mas os conglomerados e empresas transnacionais que dominam a maior parte da produção do comércio, da tecnologia e das finanças internacionais.

A Organização Mundial do Comércio (OMC), órgão que regula estas transações econômicas mundiais, vem agilizar o setor de importações e exportações para que seja devidamente regulada a atividade de trabalhadores (da mão de obra), bem como a exploração do trabalho infantil e escravo. A partir daí surge a "cláusula social", indicada pela OMC, que regula os trabalhos neste sentido, para que não haja discriminação racial e exploração de trabalho infantil.

Outro ponto é a grande retomada do desenvolvimento mundial, que se dá graças às grandes receitas de capital no que se refere à importação e exportação.

Há que se falar também das atividades ilícitas ocorridas neste "intercâmbio" financeiro. O Direito Internacional surge neste contexto para dirimir e esclarecer tais problemas, pois estas transações devem ser regidas sob alegação de tratados internacionais e contratos pré-estabelecidos.

b) Política: no contexto político, Vieira (2002) afirma que: "o Estado continua sendo um ator fundamental da política nacional". Essa afirmação refere-se ao fato de que as atividades estatais são primordiais no que diz respeito ao contexto da globalização. Este fato pode ser observado no momento em que surge a crise global, que se deu num primeiro momento pelo empobrecimento do Terceiro Mundo e a subsequente atuação do Fundo Monetário Internacional (FMI) para regular a situação econômica destes países de forma social, na qual todos colaboraram. No segundo momento ocorre a queda do comunismo e da ex-URSS, fortalecendo a economia do Leste Europeu. Por fim, inicia-se a fase de pagamento das dívidas do Terceiro Mundo junto ao FMI, pois os bancos internacionais entram em crise. Iniciase aí um conflito étnico, religioso e econômico para superar esta crise de forma que não se deixe o país de Terceiro Mundo em situação de calamidade. As transformações e evoluções dos países de primeiro mundo com a globalização vêm amenizar os problemas desta "crise".

c) Social: neste aspecto pode-se dizer que a globalização deixa a desejar. $O$ mundo ficou pobre e carente com tantas informações, o crescimento desenfreado do 
comércio, a mão de obra cada vez mais qualificada e os avanços tecnológicos deixaram a população menos favorecida, sem condições de acompanhá-los e sem a menor perspectiva de melhora de vida. Nesse sentido, Vieira (2002, p. 87) observa que "o século 21 conduziu a economia global a uma encruzilhada: o processo de reestruturação econômica levou o mundo em desenvolvimento à fome e grandes parcelas da população ao empobrecimento".

Pode-se constatar que a população encontra-se empobrecida e que a fome avassala não só países da América Latina, mas também da África, do Oriente Médio, entre outros. Um fator que pode ser analisado, como exemplo, é o do trabalho industrial, em que tantas fábricas substituem o trabalho humano pelo informatizado e ainda exigem melhores qualificações para a operação de máquinas e computadores. "A globalização da pobreza ocorre em época de notável progresso tecnológico nas áreas da engenharia de produção, telecomunicação, computadores e biotecnologia" (VIEIRA, 2002, p. 90).

Verifica-se, portanto que, mesmo com o avanço tecnológico, a população mundial não consegue superar as dificuldades e a cada dia que passa torna-se mais empobrecida e carente de políticas públicas nas áreas de saúde, educação, lazer, entre outros direitos básicos. Isso muda, acima de tudo, as relações entre o Estado e o cidadão, que passa a exigir uma ampla e complexa gama de programas governamentais com o objetivo de concretizar os seus direitos e assim tornar-se um cidadão com gozo de sua cidadania.

\section{CIDADANIA}

Deve-se analisar o conceito de cidadania de forma restrita para evitar seu desvirtuamento sob aspectos de direito social, como descreve Marshall (1967), que previa a cidadania composta de direitos civis e políticos - entendidos como direitos de primeira geração; e direitos sociais - direitos de segunda geração.

Os direitos civis são caracterizados, principalmente, pela ideia de humanismo, sob o direito individualista de ir, vir, gozar, dispor, possuir igualdade e liberdade, os quais embasavam uma ideia liberal clássica no século 21. 
Esta geração de direitos, segundo Vieira (2002, p. 32), "abrange os chamados direitos negativos, ou seja, os direitos estabelecidos contra o Estado". Surge daí a afirmação de Norberto Bobbio de que entre eles estão "todos aqueles direitos que tendem a limitar o poder do Estado e a reservar para o indivíduo, ou para os grupos particulares, uma esfera de liberdade em relação ao Estado" (apud VIEIRA, 2002, p. 32).

Estes direitos, segundo Bedin (2002, p. 43),

\begin{abstract}
estabelecem um marco divisório entre a esfera pública (Estado) e a esfera privada (sociedade civil). Esta distinção entre a esfera pública e a esfera privada - é bom ressaltar - é uma das características fundamentais da sociedade moderna, e é a partir dela que se estrutura o pensamento liberal e o pensamento democrático.

Estes direitos de primeira geração, por outro lado, são tão importantes que Claude Lefort chegou a afirmar que eles constituem a pedra de fundação da democracia moderna e que, portanto, "onde sofrerem restrições todo o edifício democrático corre o risco de desmoronar".
\end{abstract}

Já os direitos políticos ligavam-se à idéia social de associação, organização de grupos, os quais se destacaram em meio ao século 19. Quanto a esta segunda geração de direitos, Bedin (2002, p. 56) traz o entendimento de Vera Regina Pereira de Andrade (1993), segundo a qual, esta se processou "na esteira das potencialidades democráticas da cidadania civil, ou seja, na esteira dos direitos civis" e, como tal, pode ser vista como desdobramento natural da primeira geração de direitos.

Com a chegada do século 21, pode-se dizer que a busca por alguns direitos de necessidade humana foram surgindo e obtendo grande destaque com os movimentos cooperativistas e sindicais. Assim, trabalho, saúde, educação, entre outros, foram defendidos e buscados, formando a categoria dos direitos reais provindos dos direitos formais. E, com isto, esta terceira geração de direitos pode ser compreendida como "direitos de créditos", ou seja, os direitos que tornam o Estado devedor dos indivíduos, particularmente dos indivíduos trabalhadores e dos indivíduos marginalizados, no que se refere à obrigação de realizar ações concretas, visando a garantir-Ihes um mínimo de igualdade e de bem-estar social. Estes direitos, portanto, não são direitos estabelecidos contra 0 Estado ou direitos de participar no Estado, mas sim direitos garantidos através ou por meio do Estado. 
Com a transformação do Estado e a crise dos direitos sociais daí decorrentes impuseram duras perdas ao sistema democrático e à cidadania. A competição de mercado e a acumulação de capitais vêm se afirmando em meio a um movimento globalizado, monitorado por grupos de poderes que também vão se mundializando e determinando a forma e o conteúdo das intervenções estatais, independentemente da vontade da cidadania. (BERTASO, 2002, p. 407).

Há de se falar, também, na transição sofrida com a chegada da Idade Moderna, quando o contrato social veio fortalecer a ideia de justiça, pois parte do princípio de que os homens são livres e iguais e estabelecem um contrato para suprir a necessidade de ordem e normas jurídicas legais. Ocorre aí, segundo Weber, a substituição da tradição pela racionalização, a retomada do formalismo lógico que, segundo ele, levará os três tipos ideais de legitimidade: carismática, tradicional e racional-legal. Neste sentido, Bedin (2002, p. 80) esclarece que:

Assim, como se pode ver, havia um paradoxo: a direita tradicional acusava os direitos do homem de serem abstratos demais e a esquerda tradicional acusava os mesmos, ao contrário, de serem concretos demais. Então, poderíamos nos perguntar, neste momento: afinal de contas, quem tinha razão? Entendemos, juntamente com Norberto Bobbio (1992) e Claude Lefort (1987), que nenhuma das posturas, pois a direita tradicional esquecia de contrariar o arbítrio do Antigo Regime e a esquerda tradicional insistia em confundir a origem histórica com questões de princípios.

Salienta-se que não existe interesse na postura política adotada para que os direitos sejam efetivados, o que importa é que por meio desta efetivação o cidadão desenvolva sua cidadania.

No conceito de cidadania fala-se em direitos e deveres, os quais enfocam o cidadão como pessoa, formador de opiniões e transformador da sociedade, um ser político que, devido à necessidade de mudanças e de avanços exigidos pelo mundo, torna-se frustrado e com poucas perspectivas.

A cidadania política no Brasil e no mundo reflete-se por ações que transformam a vida da população, tanto no âmbito político quanto social. O cidadão espera de seus governantes, por meio de instrumentos políticos, uma melhoria considerável no estilo e na qualidade de vida, o que acaba transformando o dever do cidadão governante de coordenar trabalhos e projetos em obrigação, tornando cada vez mais difícil sua atuação. 
Não se pode deixar de ressaltar o civismo como marca do cidadão, pelo menos deve ser tido como tal e até mesmo confundido com ele. Nas palavras de Leca:

[...] cidadania, muitas vezes apresentada como civismo, seria composta de três laços principais. O primeiro seria a inteligibilidade do mundo político pelo cidadão; o segundo a empatia enquanto capacidade de colocar-se no lugar de outros cidadãos para apreender seus interesses e justificações; o terceiro, a civilidade que se refere ao conhecimento interindividual, possuindo caráter mais civil, enquanto empatia apresenta caráter mais cívico. (apud VIEIRA, 2002, p. 26).

O fato é que se cada homem, na qualidade de "operador de Direito", organizado em sindicatos e comunidade, com todas as garantias que lhe são dadas, realizasse seu trabalho de forma honrada e de acordo com a necessidade do grupo, com certeza, o exercício de cidadão de Direito estaria sendo suprido. Infelizmente, porém, não é isso que ocorre. Cita-se aqui o exemplo do Direito Ambiental, que tem sido assunto de abordagem pontual em face da globalização e dos prejuízos causados à saúde da população. Na realidade, porém, de quem é a culpa? Cada pessoa deve se conscientizar de que os males causados ao meio ambiente se refletem na saúde, como câncer, ar poluído, águas impotáveis, alimentos envenenados, tudo isso pró-agressão do cidadão que deveria pensar no seu dever de manter a qualidade de vida e não apenas cobrá-la de seus representantes.

\subsection{Cidadão e a sociedade civil}

Existem correntes que entendem o contexto de cidadania como a construção de um Estado Democrático de Direito, podendo-se citar o liberalismo como exemplo. $\mathrm{E}$, de outro lado, existem pensadores que entendem que o Direito está inserido na Moral, tornando-se assim elemento estruturador da democracia. Pode-se mencionar também outros doutrinadores que relacionam a visão de Direito aos interesses econômicos de classes a fim de enfatizar a noção de sociedade.

A partir desse entendimento surge a expressão "Direito Alternativo", usada por alguns para defender as classes menos favorecidas da sociedade. Trata-se de direitos da classe trabalhadora e oprimida em geral, que parte do pressuposto de que este Direito ampara as classes de baixa renda, à procura da ressocialização do 
indivíduo como cidadão de direitos e deveres. Ele não possui, portanto, apenas o caráter punitivo, que não traz nenhum tipo de benefício a este cidadão, que vem sendo explorado e exigido na sociedade até os dias atuais.

A noção de democracia também deve ser explorada neste aspecto, pois vem sendo usada como ideologia de grupos dominantes. Ela não é só usada como regime político em eleições e discussões, mas é uma "forma de existência social".

Ressalta Vieira (2002, p. 40) a este respeito que:

Democracia é uma sociedade aberta, que permite sempre a criação de novos direitos. Os movimentos sociais, nas suas lutas, transformaram os direitos declarados formalmente em direitos reais. As lutas pela liberdade e igualdade ampliaram os direitos civis e políticos da cidadania, criaram os direitos sociais, os direitos das chamadas "minorias", mulheres e crianças, idosos, minorias étnicas e sexuais e, pelas lutas ecológicas, o direito de um meio ambiente sadio.

O Estado Democrático pode considerar um conflito legítimo, não só trabalhando em questões de interesse e necessidades particulares existentes na sociedade, mas sim instituindo-os como Direitos Universais reconhecidos formalmente. Os indivíduos pertencentes a um determinado Estado organizam-se em grupos, associações, movimentos políticos, sindicatos e partidos, constituindo outro poder limitador. Como menciona Chauí (1984), uma sociedade democrática não cessa de trabalhar suas divisões e diferenças internas, e está sempre aberta à ampliação dos direitos existentes e à criação de novos Direitos.

Pode-se dizer, assim, que a cidadania se define pelos princípios democráticos e constitui-se na criação de espaços sociais de luta e de instituições que significam conquista de lutas sociais, políticas e econômicas. Neste contexto, deve-se entender cidadania sob o aspecto de que o cidadão, portador de direitos e deveres, é criador de seu próprio Direito, tendo participação importante e decisiva nos principais acontecimentos econômicos e sociais do país.

Cabe ao Direito, no entanto, regular as relações entre indivíduos e o Estado, entre os direitos civis (alimentação, moradia, educação, saúde), os deveres cívicos e os direitos e deveres da cidadania.

De maneira "democrática", o cidadão pode reivindicar seus direitos e transformá-los em missão para a transformação de uma sociedade mais justa e igualitária. Deve atribuir os espaços e problemas a todas as classes sociais, 
contribuindo para a humanização da sociedade. E, além disso, fazer com que cada um entenda o poder de dirimir problemas, encontrar soluções para transformar o mundo em um lugar justo, solidário, onde as pessoas possam ter ideais de liberdade e igualdade. A sociedade poderá cumprir um papel libertador e contribuir para a emancipação humana, abrindo novos espaços de liberdade (GUATTARI, 1987, 1990 apud VIEIRA, 2002, p. 41).

Cada um, como cidadão, tem o dever de contribuir para o desenvolvimento e conservação de seu Estado. A cidadania não deve ser entendida como obrigação, mas como conservação de uma vida saudável, digna e responsável para com a sociedade.

\subsection{Cidadania e globalização: uma dimensão social}

No conceito de cidadania existem alguns pontos a serem discutidos quanto ao aspecto social do cidadão brasileiro. A certeza da impunidade é fator primordial no contexto de subdesenvolvimento brasileiro, visto que o Estado tem sido pouco eficaz em suas atitudes. De início pode-se constatar que os direitos políticos foram concebidos antes que os brasileiros os tivessem adquirido por conta e vontade própria.

Castro Júnior (2002, p. 256) observa que:

A Independência foi proclamada em 1822 e as mais importantes decisões
da República brasileira foram tomadas pelas elites, tal como a sua
proclamação, em 1889, feita através de articulações, pelas cúpulas, entre
militares e liberais, sem a participação efetiva do povo, ou seja, foi um
processo imposto de cima para baixo, com o Estado paternalista
concedendo direitos políticos.

Pode-se afirmar, então, que o povo não teve participação ativa para requerer seus direitos, o que constituiu uma "crise" na consolidação da consciência de cidadania no Brasil. Como um bom exemplo deste momento pode-se citar o art. 179, XIII da Constituição Imperial "outorgada, não promulgada, de 1824, que dispõe sobre a igualdade de todos perante a lei, embora a escravidão tenha se perpetuado durante todo o Período Imperial, estendendo-se, ainda que de forma não explícita, até o século XXI" (CASTRO JÚNIOR, 2002, p. 257). 
O texto apresenta um paradoxo, pois se tem uma Carta que foi outorgada em meio a contradições entre o poder Monárquico e Absolutista e o poder do povo, que expressa que todos são iguais perante a lei. Observa-se, porém, que no contexto social da época, a Constituição não atende ao que ela mesma propõe ao estabelecer que "todos são iguais".

Um ponto a ser examinado é o do Período Colonial, em que se pode comprovar a injustiça diante dos direitos civis. Nosso país herdou deste período a escravidão que negava ao cidadão negro os direitos à dignidade humana, mantendo-o submisso aos latifúndios. Desse modo, de norte a sul do país o regime de escravatura dos negros tratava-os como meras peças baratas, fornecedores de mão de obra, subjugados aos mandos e desmandos de seus senhores. Mesmo com a Abolição, em 1888, percebe-se que formalmente a liberdade foi concedida aos negros, mas materialmente até os dias de hoje são constatadas injustiças em vários lugares do país.

No governo de Getúlio Vargas, com a criação do Ministério do Trabalho e outorga da Consolidação das Leis Trabalhistas - CLT (Decreto-Lei no 5.452, de 01 de maio de 1943), o povo teve concessão de direitos sociais nas legislações constitucional e infraconstitucional. Não se pode negar que no período de 1930 a 1945 os direitos sociais tiveram grande ampliação, pois foi quando se implantou a legislação trabalhista e previdenciária. A partir deste momento iniciou-se a evolução de direitos sociais, ocorrendo a sua inversão à frente dos direitos políticos. A construção de uma nova cidadania culminou com a chegada do século 21, quando se passou a ter uma Constituição promulgada e não mais outorgada.

Há de se considerar que diante dos fatos ocorridos durante o processo histórico, já que antes não houve um fortalecimento da sociedade civil, ainda hoje se percebe a dificuldade na evolução da cidadania, sendo necessários fatos e interesses para que se perceba o desenvolvimento do cidadão enquanto homem e ser humano. Neste sentido:

reconhece-se que a cidadania, incluindo-se, portanto, a efetividade dos direitos civis, dentre os quais o associativismo e, por consequência o cooperativismo, pois esse é uma solução bastante eficiente para a geração de emprego e renda, decorre de um processo histórico que, por sua vez, sofre um processo de lutas e de construção ideológica, juntamente com 
outras categorias, tais como Estado e nação. (CASTRO JÚNIOR, 2002, p. 259).

Sabe-se que com o fim da Segunda Guerra Mundial e com a chegada do modelo de democracia ocidental, o Estado de Direito assume um novo papel na consolidação dos direitos fundamentais dispostos nas Constituições.

Deve-se salientar que a consolidação da cidadania é requisito primordial para a redução das desigualdades sociais, e que os juristas e a sociedade como um todo têm papel fundamental para fazerem valer os direitos conquistados.

No Brasil, a realidade demonstra que a consciência do brasileiro não possibilita o exercício da cidadania, pois devido às fáceis "ilusões" criadas, estas tornam-se influência propícia aos detentores do poder, reféns do próprio sistema.

Segundo Posenato (2002, p. 243):

O complexo de direitos e deveres que as eventuais teses sobre a cidadania construirão, não pode ser deixada à deriva, mas pressupõe precisas escolhas éticas. No ordenamento brasileiro atual, a ordem não deve ser abandonada à autodisciplina dos indivíduos e a ação somente exterior da força pública. Deve basear-se em uma ética pública que descentralize o sujeito, incentivando-o a olhar para si próprio como parte importante de uma totalidade e, enfim, induzindo-o a transformar esta totalidade no seu próprio destino, na sua própria verdadeira e profunda identidade.

Conclui-se, portanto, que para que a cidadania represente um avanço na sociedade há necessidade da realização de experiências democráticas relativas aos direitos civis, políticos e sociais.

\subsection{A globalização e o direito}

Com a chegada dos novos tempos, e com eles o avanço nas mais diversas áreas, a vida dos indivíduos também mudou. Ampliaram-se e criaram-se paradigmas para estruturar a nova sociedade, sendo criadas novas metas, novos modelos de paradigmas para a economia, a política, a sociedade e a área jurídica.

A globalização da economia foi primordial para esses avanços. A chegada do século 21 trouxe mudanças tecnológicas associadas às mudanças culturais, pois estas se tornaram necessárias a partir do momento em que se criou uma visão global. 
Nem todos os indivíduos, entretanto, têm acesso a essas mudanças, pois elas requerem alteração de comportamento, de pensamento e até de ação no tocante a "modos comerciais de agir", possibilidades de compra e de participação nos avanços.

O Direito modificou-se em vários campos com a chegada da globalização. $\mathrm{Na}$ economia utilizou-se da internacionalização dos mercados, da organização de serviços legais e de acordos internacionais. Neste contexto podemos observar as linhas do Direito que sofreram mudanças, como por exemplo, o Direito Ambiental, o Direito Social (na linha da justiça social), os Direitos Humanos e Democráticos.

A importância deste assunto cresce devido às transformações da sociedade industrial e econômica. A globalização torna-se primordial pelas relações jurídicas entre Estado e Direito, e Direito e Democracia.

Há de se falar, também, da globalização do setor industrial, em que o modo de produção europeu transformou o mundo globalizado e supriu as suas necessidades mercantis.

\section{CONSIDERAÇÕES FINAIS}

Com a chegada do século 21 inúmeras foram as inovações nas mais diversas áreas do conhecimento. $\mathrm{O}$ que ficou esquecido, porém, é que o homem cidadão está carente de cultura e cidadania em sua forma mais definida. Há muito que se trabalhar a questão da globalização em função da necessidade de entendimento, de entrosamento por parte da população.

Os avanços científicos são comprovados mediante a descoberta de novos tratamentos para doenças, enquanto a economia trata de mercados, importações e exportações de maneira diferenciada, sobretudo com melhor relacionamento entre os países. O Estado está cada vez mais social e preocupado com as relações econômicas internacionais sem se dar conta de que ainda existem miséria e fome no mundo.

Há de se mencionar ainda que grandes mudanças ocorreram no mundo para melhorar as relações e sanar os problemas. Pode-se dizer, porém, que o mundo ainda vive sob grandes expectativas e está em transição com a chegada de novos 
tempos e grandes avanços, e que necessita de melhores políticas públicas que exigem grandes mudanças a serem feitas na ordem social com relação ao cidadão e ao mundo globalizado que o cerca.

\section{REFERÊNCIAS}

BEDIN, Gilmar Antonio. Os direitos do homem e o neoliberalismo. 3. ed. rev. e ampl. ljuí, RS: Ed. Unijuí, 2002. 200 p. (Coleção Ciências Sociais).

BERTASO, João Martins. A cidadania moderna: a leitura de uma transformação. In: DAL RI JÚNIOR, Arno; OLIVEIRA, Odette Maria de (Orgs). Cidadania e nacionalidade: efeitos e perspectivas nacionais e regionais-globais. Ijuí: Ed. Unijuí, 2002.544 p. (Coleção Ciências Sociais).

CASTELLS, Manuel. Fin de milênio. Versión castellana de Carmen Martinez Gimeno. Madrid: Alianza, 1998. v. 3.

CASTRO JÚNIOR, Osvaldo Agripio de. A cidadania brasileira e o papel dos operadores do Direito na busca de sua consolidação. In: DAL RI JÚNIOR, Arno; OLIVEIRA, Odette Maria de (Orgs). Cidadania e nacionalidade: efeitos e perspectivas nacionais e regionais-globais. ljuí: Ed. Unijuí, 2002.544 p. (Coleção Ciências Sociais).

CHAUÍ, Marilena. O que é ideologia? 14 ed. São Paulo: Braziliense, 1984.

FARIA José Eduardo. Direito na economia globalizada. São Paulo: Malheiros, 2002.

FERRAJOLI, Luigi: A soberania no mundo moderno. São Paulo: Martins Fontes, 2002.

GIDDENS, Anthony. As conseqüências da modernidade. Trad. de Raul Fiker. São Paulo: UNESP, 1991.

MARSHALL, Thomas Humprey. Cidadania, classe social e status. Trad. de Meton Porto Gadella. Rio de Janeiro: Zahar, 1967.

NASCIMENTO, Valéria Ribas do. $O$ tempo das reconfigurações do constitucionalismo: os desafios para uma cultura cosmopolita. São Paulo: LTr, 2011.

POSENATO, Naiara. A evolução histórico-constitucional da nacionalidade no Brasil. In: DAL RI JÚNIOR, Arno; OLIVEIRA, Odette Maria de (Orgs). Cidadania e nacionalidade: efeitos e perspectivas nacionais e regionais-globais. Ijuí: Ed. Unijuí, 2002.544 p. (Coleção Ciências Sociais).

VIEIRA, Liszt. Cidadania e globalização. 6. ed. Rio de Janeiro: Record, 2002. 
. Os argonautas da cidadania. Rio de Janeiro: Record, 2001.

Recebido para publicação: 21/03/2012

Aceito para publicação: 19/12/2012 